Underlying dimensions in the descriptive space of perfumery odors: part II

Manuel Zarzo*

Department of Applied Statistics, Universidad Politécnica de Valencia, Camino de Vera s/n, 46022 Valencia, Spain.

*Telephone: +34 963877490; fax: +34 963877499

E-mail: mazarcas@eio.upv.es 


\title{
Underlying dimensions in the descriptive space of perfumery odors: part II
}

\author{
ABSTRACT \\ Some comprehensive compilations of odor character descriptions are available in \\ the literature, and they contain valuable information to better understand the underlying \\ dimensions of human odor psychophysics. In the present study, principal component \\ analysis was applied to two olfactory databases of perfumery materials publicly available, \\ which are comprised by those odor descriptors most frequently used in perfumery. The \\ projection of descriptors over the two principal axes (two-component solution) led to \\ related plots, which are also similar to the one obtained in a previous study (Zarzo, 2008) \\ [Zarzo, M. (2008). Relevant psychological dimensions in the perceptual space of \\ perfumery odors. Food Qual. Pref. 19, 315-322]. Although the descriptive space of odors is \\ highly multidimensional, our results suggest that it is possible to reach a consensus about \\ how to project perfumery scents on a two-dimensional map, and how to interpret the \\ dimensions of that sensory map. One of them discriminates light vs. heavy odors; the \\ orthogonal axis was correlated with hedonic tones, but it is better interpreted as an \\ underlying latent structure that distinguishes feminine vs. masculine cosmetic scents.
}

\section{KEYWORDS}

Fragrance, sensory map, olfactory database, odor character descriptor

\author{
ABBREVIATIONS \\ HT: hedonic tone \\ PC: principal component \\ SI: substantivity index
}




\section{INTRODUCTION}

Two-dimensional (2-D) representations of flavors are valuable tools for sensory analysis. The beer flavor wheel displays different classes around a central point resembling the radii of a wheel. Classes next to each other are supposed to be similar, while those located in opposite positions represent dissimilar flavors (Meilgaard et al., 1979). Similar representations have been developed in other areas, like the wine aroma wheel (Noble et al., 1987), the coffee taster’s flavor wheel (Lingle, 1992) and the sensory wheel for virgin olive oil (Mojet \& De Jong, 1994).

Perfumes are complex mixtures of scents, and their sensory description becomes difficult for naive consumers. With thousands of perfumes available in the market, shopping for a new fragrance can become confusing. In order to allow a better communication between perfume retailers and consumers, it would be helpful to use a standard 2-D sensory map of odor descriptors, which would serve as a basis to understand the classification of fragrances. Unfortunately, such standard map does not exist yet probably because there is not an agreement about the most appropriate scientific methodology to reach a consensus. Perfumery companies have developed different schemes for classifying commercial fragrances, such as the Discodor (Harder, 1979), Analogies of Givaudan (Figs. 3 and 4 of Thiboud, 1991), the Drom Fragrance Circle, the natural perfume wheel of Aftelier (2006), the Rosace of Firmenich, the Hexagon of fragrance families (Haldiman \& Schuenemann, 1990), and some others mentioned by Jellinek (1992). Additional sensory maps of scents have been developed by individual perfumers like Jellinek (1997) and Edwards (2010). Despite the amount of available olfactory representations in this field, their comparison is difficult because the relative position of descriptors often differs considerably, and only few odor maps can be matched 
with a reasonable agreement. The classification of perfumes is an area of scientific interest (Teixeira et al., 2014), but few efforts have been carried out to compare such classifications aimed at providing certain consensus scheme.

The most scientific way to develop a sensory map of scents is to obtain a large compilation of odor descriptions and to analyze them with multivariate statistical methods. Such approach has been carried out by different researchers (Abe et al., 1990; Chastrette et al., 1991; Jaubert et al., 1995; Madany-Mamlouk et al., 2003; Zarzo \& Stanton, 2006). However, the sensory maps obtained in these works are difficult to compare. Given such disparity and the fact that odor percepts depend on prior learning and experience (Wilson and Stevenson, 2003; Li et al., 2006), many olfactory researchers even doubt if it is possible to reach a standard map of scents. Actually, as the olfactory descriptive space is structured in at least 10 dimensions (Castro et al., 2013), it is uncertain how to project such space over a two-factorial plane. Nonetheless, fragrances are basically cosmetic pleasant scents and, hence, many food flavors are rarely present (e.g. cheese, butter, fish, meat, garlic, etc.) as well as very unpleasant smells like putrid, sulfurous or burnt odors. Although the subspace of fragrances is very broad, reported evidence suggests that perfumery descriptors can be consistently mapped over two meaningful dimensions (Zarzo \& Stanton, 2009), but this issue still requires further empirical evidence.

The main target of the present work is to further investigate how to project the multidimensional space of perfumery descriptors over two dimensions and to check if the resulting solution is consistent with other sensory maps of scents previously reported. For this purpose, two comprehensive olfactory databases of perfumery materials are analyzed. Based on the results, three sensory wheels of fragrances are discussed. 


\section{MATERIALS AND METHODS}

\subsection{Olfactory database of Abe et al. (1990)}

From the handbooks of Arctander (1969), which contain the semantic odor description of 3102 perfumery materials, Abe et al. (1990) discarded all mixtures and obtained the words describing the smell of 1573 compounds. In total, 34 terms were applied to 30 or more aroma chemicals. For two given descriptors ( $a$ and $b$ ), the authors calculated the overlap coefficient ( $\mathrm{c}_{\mathrm{ov}}$ ) according to Eq. (1), being $\mathrm{N}_{\mathrm{ab}}$ the total number of compounds described with both terms, while $\mathrm{N}_{\mathrm{a}}$ and $\mathrm{N}_{\mathrm{b}}$ is the total number of compounds labeled with attribute $a$ and $b$, respectively.

$$
c_{o v}=\frac{N_{a b}}{\min \left(N_{a} ; N_{b}\right)} \cdot 100
$$

This coefficient is zero for descriptors that are never applied together and, conversely, the maximum value (100\%) indicates that both terms appeared always simultaneously in the odor descriptions. The array containing $\mathrm{c}_{\mathrm{ov}}$ coefficients for all possible pairs of the 34 descriptors is available (Table 2 of Abe et al., 1990). In this symmetric matrix, which will be referred to hereafter as $\mathbf{S}_{\mathrm{Abe}}$, the elements of the main diagonal are 100.

\subsection{Olfactory database of Sigma-Aldrich (2003)}

The Flavours and Fragrances Catalog of Sigma-Aldrich Fine Chemicals (SAFC) contains 881 ingredients (natural materials, aroma chemicals and mixtures) that are classified in 29 main odor categories (Sigma-Aldrich, 2003). Seven of them are subdivided into a different number of subcategories, which makes in total a pool of 82 odor descriptors (Zarzo \& Stanton, 2006). A preliminary analysis suggested that terms with less than 13 occurrences do not provide reliable information for the purpose of the present study, and 
they were disregarded. The floral category comprises 15 descriptors, but 12 of them correspond to less than 13 ingredients. Thus, all materials listed under any floral subcategory were labeled as 'floral'. The same criterion was applied to materials under the fruity, citrusy and nutty categories. As a result, the final number of descriptors was 34 .

By checking the terms assigned to each ingredient, the overlap coefficient (Eq. 1) was computed for each pair of descriptors, which led to a similarity matrix ( $\left.\mathbf{S}_{\mathrm{SAFC}}\right)$.

\subsection{Multivariate statistical analysis}

Principal component analysis (PCA) is a standard multivariate method. In most cases, the interpretation of results becomes more straightforward when the matrix columns are mean-centered prior to applying PCA. In this case, given that $\mathbf{S}_{\mathrm{Abe}}$ and $\mathbf{S}_{\mathrm{SAFC}}$ are symmetric arrays, they were double-centered using the procedure applied by Chastrette et al. (1991) (Eq. 2), which leads to transformed matrices suitable for PCA (Gower, 1966) that will be referred to as $\mathbf{T}_{\mathrm{Abe}}$ and $\mathbf{T}_{\mathrm{SAFC}}$, respectively:

$$
t_{i, j}=c_{i, j}-c_{i}-c_{j}+c
$$

where $t_{i, j}$ is each element of the double-centered matrix $\mathbf{T} ; c_{i, j}=$ element (overlap coefficient) of the similarity matrix $\mathbf{S}, \mathrm{c}_{\mathrm{i}}=$ mean of row $\mathrm{i} ; \mathrm{c}_{\mathrm{j}}=$ mean of column $\mathrm{j}$; $\mathrm{c}=$ mean

of all elements of $\mathbf{S}$. As a result of this transformation, the average of all rows and columns becomes zero. Next, PCA was applied using the software SIMCA-P 10.0 (www.umetrics.com). This procedure is equivalent to the multivariate method called Multidimensional Scaling (MDS) (Borg \& Groenen, 2005), which is a standard technique for the analysis of similarity matrices. 
In PCA, the contributions of variables (matrix columns) in the formation of a given component are called loadings, being $\mathrm{p}[1]$ the loadings in the formation of the first principal component (PC1), and so on. The plot that depicts $\mathrm{p}[2]$ vs. $\mathrm{p}[1]$, which will be called PC1/PC2 loading plot, usually highlights the main similarities and dissimilarities among descriptors and it can be regarded as a 2-D sensory map of perfumery scents (Zarzo, 2008).

By visually inspecting the loading plots with different combinations of components, it was found that certain pairs of descriptors with a strong similarity exert an excessive contribution in the model. Thus, it was necessary to reduce their influence by applying weight coefficients, as further described below, which leads to a weighted matrix ( $\mathbf{W}_{\text {Abe }}$ and $\left.\mathbf{W}_{\mathrm{SAFC}}\right)$. The resulting PC1/PC2 loading plots obtained by applying PCA to these matrices were visually inspected and compared.

\subsection{Comparison with other sensory maps}

The database of Boelens \& Haring (1981) is a large compilation of numeric odor profiles. The data were obtained by a panel of six perfumers who smelled 309 aroma chemicals and rated the odor similarity on a 0-9 scale with respect to 30 standards commonly used in perfumery. Each standard was selected as a reference material for certain odor descriptor. This compilation, which will be referred to as B-H database, was analyzed using PCA in a previous study (Zarzo, 2008). The correlation between loadings of the B-H database with respect to those from the two databases studied here was checked in order to discuss if the underlying latent structure is basically the same. 
The loading plots obtained provide valuable information to discuss fragrance wheels reported in the literature. One of them is the Discodor (Harder, 1979), which was developed by perfumers working at Haarmann \& Reimer (Germany). It was also compared with the Fragrance Wheel of Edwards (2010), the Odor Effects Diagram (Calkin \& Jellinek, 1994) and the Olfactory Spectrum (Kraft et al., 2000). The Drom Fragrance Circle (reproduced by Jasper and Wagner, 2008) is another sensory wheel comprised by 16 categories, which were conveniently arranged to resemble as much as possible the other odor maps.

\subsection{Interpretation of the underlying latent structures}

PC1 of the B-H database discriminates refreshing (light) vs. warm (heavy) odors (Zarzo, 2008). Light scents are those that evaporate quickly, while heavy odors (e.g. oriental, balsamic scents) present a high substantivity. This parameter quantifies the ability of a smell to be retained in our skin.

The H\&R Fragrance Guide (Glöss, 1991) contains the organoleptic description of 820 commercial perfumes. By counting the total number of times that a given attribute was applied to describe top, middle and base notes of perfumes in this guide, a substantivity index (SI) was calculated (see Eq. 1 of Zarzo, 2013). It takes the value zero for odors only encountered in top notes (i.e., the ones that evaporate quicker), which indicates a low substantivity. The index is 50 for those attributes merely applied to middle notes. The highest value 100 corresponds to tenacious odors only found in base notes (dry down), which implies a high persistency. The correlation between SI and p[1] loadings was checked for the olfactory databases studied here. 
Regarding PC2 of the B-H database, it was interpreted as an underlying latent structure that discriminates feminine vs. masculine scents (Zarzo, 2008). In order to further discuss this issue, I obtained the percentage of feminine and masculine perfumes in the H\&R Guide that are labeled with a given descriptor either in the top, middle or base note. These percentages provide an indirect estimation of the feminine or masculine character of descriptors.

Many studies have reported that the hedonic dimension (i.e. pleasant vs. unpleasant character) often shows up when a wide range of odors is assessed (for review, see Zarzo, 2011). In order to study if pleasantness (valence) is a salient dimension of the olfactory databases studied here, I checked the correlation of loadings with hedonic tones (HT) of descriptors obtained by Dravnieks et al. (1984), which will be called $\mathrm{HT}_{\mathrm{D} 84}$. These authors asked a panel of about 120 individuals to rate the HT of 146 odor descriptors on a numeric scale ranging from -4 for the most unpleasant to +4 for the most pleasant. In a subsequent study (Dravnieks, 1985), the same panel assessed 160 odorant samples and scored each based on the applicability of the 146 descriptors. In this database, PC1 corresponds to the hedonic dimension (Khan et al., 2007; Koulakov et al., 2011) and, hence, p[1] loadings are correlated with $\mathrm{HT}_{\mathrm{D} 84}\left(\mathrm{r}=0.75, \mathrm{p}<10^{-4}\right)$. Thus, such $\mathrm{p}[1]$ values can be considered as hedonic tones, and they were multiplied by 100 to obtain a handy scale from about -20 to 20 that will be referred to as $\mathrm{HT}_{\mathrm{D} 85}$.

\section{RESULTS}

\subsection{Olfactory database of Abe et al. (1990)}

'Pungent' is usually applied to describe irritating chemesthetic olfactory sensations because it comes from the Latin 'pungente' (prickly), which is a tactile stimulation. Such 
sensations do not fit into the traditional categories of odor quality and, consequently, the row and column corresponding to this descriptor were discarded.

The PC1/PC2 and PC3/PC4 loading plots obtained from the $\mathbf{T}_{\text {Abe }}$ matrix are depicted in Fig. 1. PC1 explains $19 \%$ of the data variability $\left(\mathrm{R}_{\mathrm{x}}^{2}=0.19\right)$ and it is essentially determined by fruity descriptors. PC2 $\left(\mathrm{R}_{\mathrm{x}}^{2}=0.11\right)$ basically accounts for 'green' and related descriptors ('vegetable' and 'leafy'), which makes sense because 'green' was the third term most frequently encountered in the database. It refers to odors reminiscent of freshly cut grass, leaves, stems, and so on (Müller, 1992).

\section{[FIGURE 1 NEAR HERE]}

Caramel and vanilla are similar scents often classified as balsamic (Zarzo \& Stanton, 2006). However, in the database of Abe et al. (1990), 'caramelic' is neither related with 'vanilla' nor with 'balsamic' ( $\mathrm{c}_{\mathrm{ov}}=0$ in both cases). Thus, it was discarded. 'Winey' yields certain similarity with 'caramelic' ( $\mathrm{c}_{\mathrm{ov}}=20 \%$ ) and 'fruity' ( $\left.\mathrm{c}_{\mathrm{ov}}=62 \%\right)$, but it is rarely used in perfumery and it was also disregarded.

The pairs of descriptors with highest overlap coefficient in $\mathbf{T}_{\mathrm{Abe}}$, in decreasing order, are the following: 'green’-‘vegetable’, ‘fruity’-'banana’, ‘fruity’-‘apple’, ‘fruity’‘pineapple’, ‘floral’-‘hyacinth’, 'green’-‘leafy’, ‘minty’-‘camphoraceous', ‘vanilla’'balsamic', ‘woody'-‘camphoraceous', 'rosy’-‘hyacinth', ‘vinous’-‘fruity', ‘musky’'animal', ‘fruity’-‘orange', ‘woody’-‘medicinal', and 'waxy'-‘fatty'. These similarities, which are well known in perfumery (Chastrette et al., 1988, 1991), are reflected in the loading plots shown in Fig. 1 because pairs of attributes strongly associated appear close to each other. 
It turns out that PC1 is determined by 'apple', 'banana’, 'pineapple', and fruity', which reflects obvious relationships. Similarly, PC2 is strongly influenced by the wellknown similarities between 'green', 'vegetable' and 'leafy'. Hence, the resulting loading plot does not provide useful information. In order to overcome this limitation, one option is to remove the redundant descriptors, for example by leaving 'fruity' and discarding 'apple', 'banana' and 'pineapple'. An alternative approach commonly used in PCA (Jolliffe, 2002) and also in MDS (Borg \& Groenen, 2005) is to keep all descriptors and use weight coefficients with those sets of terms that strongly affect PCs according to Fig. 1. A similar methodology has been used by other authors (Buja \& Swayne, 2002). The most appropriate values of these coefficients were determined by progressively reducing the weight (i.e., $0.9,0.8,0.7$, and so on) for the most similar pairs of terms and checking next the resulting loading plots.

Thus, in order to decrease the influence of related descriptors in the PCA model, the

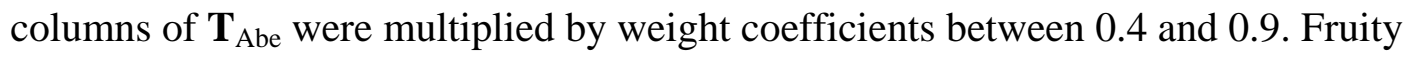
descriptors are the ones most strongly affecting PC1 and, hence, after trying several alternatives, a coefficient of 0.5 was considered. For 'ethereal', which is related, the coefficient was 0.4. Regarding descriptors influencing PC2, a coefficient of 0.7 was used for 'green', 0.8 for 'vegetable’ and 0.6 for 'leafy'. In the case of 'minty' and ‘camphoraceous', which are also similar odors (Chastrette et al., 1988), the coefficient was 0.6. For the rest of related descriptors, values were: 0.9 ('musky', 'animal', 'balsamic', 'vanilla', 'woody', 'medicinal', and 'rosy’), 0.8 ('floral', 'hyacinth’, 'oily', 'waxy’, 'fatty’, and 'honey') and 0.7 ('gassy'). As an exception, a coefficient higher than 1 (1.3) was assigned to 'earthy' and 'musty' in order to better highlight the associations of these key descriptors. The columns of $\mathbf{T}_{\text {Abe }}$ were multiplied by these coefficients, resulting the 
weighted matrix $\mathbf{W}_{\text {Abe }}$ that was analyzed using PCA. The loadings corresponding to PC1 and PC2 are shown in Table 1.

\section{[TABLE 1 NEAR HERE]}

\subsection{Olfactory database of Sigma-Aldrich (2003)}

In the case of $\mathbf{T}_{\mathrm{SAFC}}$, PC1 explains $14 \%$ of the data variability and a lower amount corresponds to further components: PC2, 8.0\%; PC3, 7.3\%; PC4, 6.7\%. Because these values are quite similar, PC2 is ‘sensitive’ to descriptors strongly associated. The highest $\mathrm{p}$ [2] loadings (figure not shown) correspond to 'green', 'vegetable', 'fatty', 'alliaceous', and 'sulfurous'. After trying several alternatives, a weight coefficient of 0.8 was assigned to these descriptors (except 0.9 for 'vegetable') in order to reduce their excessive influence in PC2. A coefficient of 0.8 and 0.7 was assigned to 'coffee' and 'meaty', respectively, because they yield the most negative $\mathrm{p}[1]$ loadings but are rarely used in perfumery. For

other descriptors, the following weight coefficients were considered: 0.9 ('herbaceous', 'fruity', 'ethereal’, 'vanilla', and 'honey'), 1.05 ('chocolate'), and 1.1 ('earthy' and 'nutty').

\subsection{Comparison of results}

The analysis of $\mathbf{W}_{\text {Abe }}$ revealed that PC1 discriminates fruity/citrus vs. spicy odors, while PC2 separates floral vs. non-floral scents. Similar polarities are derived from the B$\mathrm{H}$ database (loadings shown in Table 1). Actually, the correlation between $\mathrm{p}[1]$ from $\mathbf{W}_{\text {Abe }}$ and the B-H database $\left(p[1]_{B-H}\right)$ is statistically significant $(r=0.77, p=0.0009, n=15)$. Additionally, $\mathrm{p}[2]$ values from both arrays are also correlated $(\mathrm{r}=0.67, \mathrm{p}=0.006)$, which implies that the underlying latent structures can be interpreted in the same way. 
By contrast, $\mathrm{p}[2]_{\mathrm{SAFC}}$ yields a statistically significant correlation with $\mathrm{p}[1]_{\mathrm{B}-\mathrm{H}}(\mathrm{r}=$ 0.82, $\mathrm{p}<10^{-4}, \mathrm{n}=18$ ) while $\mathrm{p}[1]_{\mathrm{SAFC}}$ is correlated with $\mathrm{p}[2]_{\mathrm{B}-\mathrm{H}}(\mathrm{r}=0.77, \mathrm{p}=0.0002)$, which indicates an equivalent underlying structure if the loading plot from $\mathbf{W}_{\mathrm{SAFC}}$ is rotated $90^{\circ}$. Taking into account this rotation of components, average 'consensus' loadings were obtained (Eqs. 3 and 4). If the loadings were available only from one database, such values were considered as 'consensus'. For example, $\mathrm{p}[1]_{\mathrm{Abe}}$ is missing in the case of ‘alliaceous' and, hence, $\mathrm{p}[\mathrm{x}]=\mathrm{p}[2]_{\mathrm{SAFC}}$. Similarly, for 'orange’, $\mathrm{p}[\mathrm{x}]=\mathrm{p}[1]_{\mathrm{Abe}}$.

$$
\begin{aligned}
& p[x]=\frac{p[1]_{A b e}+p[2]_{S A F C}}{2} \\
& p[y]=\frac{p[2]_{A b e}+p[1]_{S A F C}}{2}
\end{aligned}
$$

The plot $\mathrm{p}[\mathrm{y}]$ vs. $\mathrm{p}[\mathrm{x}]$ summarizes the main information of the two databases, and it was superimposed with the PC1/PC2 plot from the B-H database (Fig. 2). The agreement between both plots is reasonably good. It turns out that $\mathrm{p}[\mathrm{x}]$ values are strongly correlated with $\mathrm{p}[1]_{\mathrm{B}-\mathrm{H}}\left(\mathrm{r}=0.84, \mathrm{p}<10^{-4}, \mathrm{n}=18\right)$, as well as $\mathrm{p}[\mathrm{y}]$ compared with $\mathrm{p}[2]_{\mathrm{B}-\mathrm{H}}(\mathrm{r}=0.79, \mathrm{p}$ $=0.0001$ ), which is evidenced by the consistent position of equivalent descriptors in Fig. 2 .

\section{[FIGURE 2 NEAR HERE]}

The Discodor (Harder, 1979) is a sensory wheel that displays 17 perfumery odor categories. 'Floral' is located at the center, but this criterion is arguable. Based on the results reported here (Fig. 2) and previous studies (Zarzo \& Stanton, 2009), the floral category was placed between 'sweet' and 'fruity'. The resulting representation was compared with the Fragrance Wheel (Edwards, 2010). In both odor wheels depicted in Fig. 3 , the sequence of odor classes around the central point is the same as originally proposed by the authors, but they were conveniently rotated to achieve the best possible consistency. The Odor Effects Diagram proposed by Calkin \& Jellinek (1994) is also illustrated for 
clarity purposes. By carefully checking Fig. 3 and comparing it with Fig. 2, it seems convenient to reorganize some categories of the Discodor (outer descriptors in italics).

\section{[FIGURE 3 NEAR HERE]}

The fragrance wheel developed by Drom Fragrances International KG (Baierbrunn, Germany) is based on 16 categories, but their position is weird given that very different odors like 'citrus' and 'musk' are next to each other. The same applies to 'conifer' 'fruity' and 'lavender' - 'oriental'. Based on the results reported here, the 16 categories were conveniently arranged (Fig. 4) to resemble as much as possible other odor maps (Figs. 2 and 3).

[FIGURE 4 NEAR HERE]

\subsection{Interpretation of the underlying latent structures}

Consensus loadings $\mathrm{p}[\mathrm{x}]$ and $\mathrm{p}[\mathrm{y}]$ are available in Table 1 for 38 of the 42 descriptors. Based on the equivalent position of attributes in Fig. 2, the loadings of 'anisic', 'lavender', 'metallic', and 'powdery', which are available from the B-H matrix, were added to the list of consensus loadings for the following statistical analysis.

It turns out that the substantivity index (values in Table 1) is significantly correlated with $p[x](r=-0.61, p=0.002, n=24)$ and $p[1]_{B-H}(r=-0.78, p=0.0003, n=17)$, but neither with $\mathrm{p}[\mathrm{y}]$ nor $\mathrm{p}[2]_{\mathrm{B}-\mathrm{H}}(\mathrm{p} \geq 0.7)$. Thus, the horizontal axis of Fig. 2 discriminates light vs. heavy smells and reflects odorant substantivity, as discussed recently (Zarzo, 2013).

The values $\% \mathrm{~F}$ and $\% \mathrm{M}$ in Table 1 provide information about the feminine and masculine character of odor descriptors. 'Animal' and 'vegetable' are not present in the H\&R guide, and the values of SI, \%F and \%M included in Table 1 for them correspond to 
civet and clary sage, respectively, which were the reference materials for such descriptors in the B-H database. Analogously, 'earthy' and 'musty' are absent in the H\&R guide, and both were matched with 'mossy', which is a closely related odor (Zarzo \& Stanton, 2009). 'Minty' was matched with 'peppermint'. 'Waxy' was paired with 'aldehydic', which are related descriptors in perfumery (Chastrette et al., 1988).

The parameter $\% \mathrm{~F}-\% \mathrm{M}$ takes positive values for descriptors applied more often to women's perfumes, while the opposite applies for negative values. Remarkably, this parameter is significantly correlated with $\mathrm{p}[2]_{\mathrm{B}-\mathrm{H}}(\mathrm{r}=0.68, \mathrm{p}=0.003, \mathrm{n}=17)$, as well as with $\mathrm{p}[\mathrm{y}](\mathrm{r}=0.64, \mathrm{p}=0.0007, \mathrm{n}=24)$, but neither with $\mathrm{p}[1]_{\mathrm{B}-\mathrm{H}}$ nor $\mathrm{p}[\mathrm{x}](\mathrm{p} \geq 0.5)$. This result supports the hypothesis that the vertical axis of Fig. 2 discriminates feminine vs. masculine cosmetic scents (Zarzo \& Stanton, 2009).

Nonetheless, given that floral and sweet scents are very pleasant while some descriptors at the opposite position $(\mathrm{p}[\mathrm{y}]<0)$ refer to unpleasant odors, it might be argued that $\mathrm{p}[\mathrm{y}]$ could also be interpreted as the hedonic dimension. Most descriptors in Table 1 are contained in the Dravnieks' list of 146 terms and, hence, their hedonic tones are available. 'Alliaceous' is not included, but it was matched with 'garlic_onion' which refers to the same smell type. 'Smoky’, 'gassy', and 'waxy' were matched with 'burnt_smoky', 'household gas', and 'soapy', respectively, which are related descriptors.

'Musty_earthy_moldy' is a single attribute in the Dravnieks' list, and the associated hedonic tone was assigned both to 'musty' and 'earthy'. The same applies to 'oily_fatty'. The HT of 'herbaceous', which is absent in Dravnieks' list, was computed as the average HT of 'dill' and ‘caraway', which are herbal scents. 'Vegetable', 'leafy’ and 'green’ were 
matched with 'cooked vegetables', ‘crushed grass’ and 'fresh green vegetables', respectively.

It turns out that $\mathrm{p}[2]_{\mathrm{B}-\mathrm{H}}$ values yield a moderate correlation with $\mathrm{HT}_{\mathrm{D} 84}(\mathrm{r}=0.50, \mathrm{p}$ $=0.021, \mathrm{n}=21)$ and $\mathrm{HT}_{\mathrm{D} 85}(\mathrm{r}=0.52, \mathrm{p}=0.016)$. This issue was studied previously (Table 3 of Zarzo, 2008), but the p-value was not low enough to obtain solid based conclusions. By contrast, the correlation between $\mathrm{p}[\mathrm{y}]$ and $\mathrm{HT}_{\mathrm{D} 84}$ is statistically significant $(\mathrm{r}=0.50, \mathrm{p}=$ 0.001, $\mathrm{n}=40)$, as well as with $\mathrm{HT}_{\mathrm{D} 85}\left(\mathrm{r}=0.64, \mathrm{p}<10^{-4}\right)$. This comparison implicitly assumes that hedonic tone of descriptors correspond to hedonic tone of odors which might be labeled with those descriptors. Although the re-assignment of Dravnieks' hedonic tone to other descriptors not on the list may be arguable and introduces certain uncertainty, nevertheless there is no doubt that $\mathrm{p}[\mathrm{y}]$ is significantly correlated with hedonic tones.

By further investigating this relationship, it turns out that all feminine descriptors (i.e., $\mathrm{p}[\mathrm{y}]>0.03)$ are pleasant $\left(\mathrm{HT}_{\mathrm{D} 85} \geq 0\right)$. Conversely, for descriptors with $\mathrm{p}[\mathrm{y}]<0.03$ (masculine), 8 of them are pleasing $\left(\mathrm{HT}_{\mathrm{D} 85} \geq 0\right)$ and 17 are unpleasant. Similarly, with the values of $\mathrm{HT}_{\mathrm{D} 84}$, the 12 descriptors with stronger feminine character $(\mathrm{p}[\mathrm{y}] \geq 0.04)$ are pleasant $\left(\mathrm{HT}_{\mathrm{D} 84}>0\right)$, while for the rest (masculine), $48 \%$ are pleasant and $52 \%$ are unpleasant. Thus, scents typically found in women’s fragrances are enjoyable, but some ingredients of men's perfumes may smell unfriendly. 


\section{DISCUSSION}

\subsection{Comparison of loading plots}

Although perfumers' subjectivity in establishing an olfactory description can produce discrepancies in different databases, previous studies suggest that comprehensive odor profile databases can be systematically compared (Pintore et al., 2006). Table 1 indicates the percentage of materials in the databases of Abe et al. (1990) and SAFC that are labeled with each descriptor. The values are reasonably similar, indicating a few terms that are encountered very often in perfumery ('floral', 'fruity' and 'green'), while others are rarely employed like 'buttery' or 'smoky'.

The information contained in both semantic odor profile databases is less reliable for those descriptors with fewer occurrences. This drawback does not appear using numeric odor profiles, as in the compilation of Boelens \& Haring (1981). In this database, PC1 and PC2 explain a similar amount of the total data variability (17.5\% and $14.2 \%$ respectively), which is consistent with the representation of the descriptive space of fragrances as a circle (Harder, 1979; Edwards, 2010; Mane, 2014) or a square (Jellinek, 1997) (i.e., without any dominant dimension). Consequently, it is not surprising that both dimensions may appear rotated (e.g. Richardson, 1999) or may swap when analyzing olfactory profiles. Actually, PC2 of the B-H database and the $\mathbf{W}_{\text {Abe }}$ matrix discriminates floral vs. non-floral scents, but this dimension corresponds to PC1 of $\mathbf{W}_{\mathrm{SAFC}}$ as well as the horizontal axis of other odor maps (e.g. Thiboud, 1991; Jellinek, 1997).

The average loadings $\mathrm{p}[\mathrm{x}]$ and $\mathrm{p}[\mathrm{y}]$ are tightly correlated with $\mathrm{p}[1]_{\mathrm{B}-\mathrm{H}}$ and $\mathrm{p}[2]_{\mathrm{B}-\mathrm{H}}$ values, respectively. If both plots are superimposed, the consistency is very good for most descriptors. Fig. 2 can be considered as a general 2D perfumery odor map because two 
descriptors appearing close to each other will be often applied together in the description of fragrances while, conversely, an opposite position will indicate dissimilar attributes rarely encountered simultaneously. The position of 'coffee' next to 'smoky' is appealing. The similarity between 'nutty’ and ‘woody’ has also been reported (Zarzo \& Stanton, 2009).

One cause of disparity is that the reference material that each perfumer has in mind for a given descriptor may smell quite different. For example, olibanum resinoid smells like non-sweet incense and was chosen by Boelens \& Haring (1981) as standard for 'balsamic', but a survey carried out with 120 perfumers revealed that only $2 \%$ of respondents chose this material as representative for 'balsamic' (Brud, 1986). Conversely, Arctander probably had in mind a material with sweet odor for this descriptor, which would explain its position in Fig. 2 close to 'vanilla'. Actually, in the survey of Brud (1986), most perfumers chose sweet materials like benzoin siam resinoid, tolu balsam or Peru balsam as standards for 'balsamic'. Similarly, the discrepant position of 'spicy' can be explained by the different sweet odor character between eugenol (slightly sweet), which was the reference in the B-H database, and cinnamon bark oil (clearly sweet), which is also often regarded by perfumers as standard for 'spicy’ (Brud, 1986). Actually, this descriptor yields the highest similarity with 'sweet' $\left(\mathrm{c}_{\mathrm{ov}}=30 \%\right)$ in the SAFC database.

Minty, lavender and coniferous odors share certain camphor-like notes and account for PC4 of the B-H matrix, while PC5 is basically determined by 'minty' and 'medicinal'. The camphoraceous smell is orthogonal to the main plane determined by PC1 / PC2 and, consequently, the projection of such notes over this plane may lead to discrepancies. Actually, these descriptors appear with positive $\mathrm{p}[1]_{\mathrm{B}-\mathrm{H}}$ loadings in Fig. 2 but, on the other hand, 'camphoraceous' is located next to 'medicinal'. 'Herbaceous' is usually located 
close to 'green’ (Harder, 1979; Calkin \& Jellinek, 1994), but it appears in Fig. 2 between 'green’ and ‘spicy’. Interestingly, herbaceous scents are defined as grassy-green, spicy and somewhat medicinal (Thiboud, 1991). The reason could be that many herbal odors present camphoraceous notes like rosemary and lavender. Actually, rosemary oil was the preferred reference among perfumers for 'herbal' (Brud, 1986). A three-dimensional odor map would be necessary to better depict those odors that deviate from the PC1/PC2 plot.

\subsection{Discussion of the Discodor}

Oakmoss was the reference for 'earthy' in the B-H database and it yields the most negative correlation with 'floral'. Because of this, it seems convenient to place 'oakmoss' and 'floral' at opposite positions in the Discodor. Odor descriptors below the horizontal dashed line in Fig. 3 basically account for scents most typically found in perfumes marketed to men. According to Müller (1992), such fragrances are generally less floral and contain dry notes of leather, tobacco, herbs, spices, mosses, and woods. The suggested position of descriptors in the reorganized Discodor is consistent with this criterion. The aromatic-spicy category should be regarded as spicy-sweet because 'aromatic' was used in former times to describe the fragrance impression of sweet balsams (Müller, 1992).

Amber refers to odors reminiscent of ambergris (Brud, 1986). This material exhibits different nuances such as woody, dry balsamic, somewhat tobacco-like notes and also has an erogenic note (Müller, 1992). Therefore, the suggested position of 'amber' next to 'woody', 'tobacco', and 'animalic' seems appropriate. The similarity between 'amber' and ‘woody’ has also been reported by Chasttette et al. (1991). 
The 'dry woods' family in Edwards' wheel (Fig. 3) is often called leather, after the dry, smoky scent of Russian leather. It is characterized by dry notes of tobacco and burnt wood (Edwards, 2010). Thus, the position of 'leather' close to 'dry woods' is appealing. Moreover, the similarity between 'smoky' and 'woody’ is apparent in Fig. 2.

\subsection{Discussion of the Olfactory Spectrum}

The Olfactory Spectrum reported by Kraft et al. (2000) is an odor wheel based on 8 categories in the following sequence: 'green', 'marine’, 'floral', 'spicy', 'woody', 'ambery', 'musky', and 'fruity'. According to these authors, macrocyclic musks also possess fruity aspects, which justified the position of 'musky' next to 'fruity'. However, both descriptors are usually oppositely located in olfactory representations. The proposed order to improve this odor wheel based on Fig. 3 is: 'green', 'marine', 'fruity', 'floral', ‘spicy’, 'musky’, ‘ambery', and ‘woody'. The marine category is equivalent to 'watery’ in Edwards' wheel. 'Green' is used in a broad sense comprising all odors sharing a green note ('leafy’, 'herbaceous’, 'citrus’, ‘coniferous’, 'vegetable’, and ‘earthy’). Similarly, 'spicy’ should embrace sweet spicy, oriental and balsamic odors.

\subsection{Discussion of Drom's Fragrance Circle}

With the suggested rearrangement, Drom's circle (Fig. 4) yields a reasonable agreement with Fig. 3. Moreover, the attributes associated to each category in the original representation provide information about psychological aspects of fragrances. Floral scents are the most typically cosmetic, but 'fruity' is described as original maybe because such scents recall food flavors. In fact, excess of fruitiness is to be avoided in perfumes because they would suggest food flavors rather than cosmetic products (Müller, 1992). 
Fougère (fern in French) refers to the combination of fresh herbaceous lavender notes on a mossy foundation (Müller, 1992). Hence, its position next to lavender and 'mossy wood' seems appropriate and it is equivalent to that of Edwards (2010). This category is described as masculine (Fig. 4) and, actually, about one third of men’s perfumes in the market are classified by Edwards (2010) as fougère. The masculine character of tobacco is well known in perfumery (Müller, 1992) as well as the feminine aspect of 'aldehydic' (see Table 7 of Zarzo \& Stanton, 2009), the refreshing quality of ‘citrus', and the seductive/erotic character of ‘oriental’ or musks (Jellinek, 1997).

Interestingly, ‘citrus’, 'green’, ‘herbaceous’, 'lavender’ and ‘fougère’ are basically described as stimulating. Consistent with this criterion, Richardson (1999) also found that citrus, green and herbal scents were perceived as invigorating. Tisserand (1988) associated rosemary (herbal) with the moods 'vivacity' and 'stimulant'. It seems that masculine scents $(\mathrm{p}[\mathrm{y}]>0)$ suitable for daytime wear $(\mathrm{p}[\mathrm{x}]>0)$ tend to be perceived as stimulating.

\subsection{Interpretation of underlying latent structures}

The position of descriptors in the Field of Odors (Jaubert et al., 1995) is based on their light/heavy character, as recently discussed (see Fig. 4 of Zarzo 2013). Similarly, the horizontal axis of Fig. 2 discriminates light vs. heavy odors and it is correlated with substantivity, which is a physical property of odorants. Because the light/heavy odor character is somewhat encoded by molecular structure, it might be primarily innate and evolutionarily hardwired (Zarzo, 2013).

The vertical axis is correlated with \%F-\%M and, hence, it discriminates feminine vs. masculine descriptors. This distinction can be traced back to Linnaeous (1756) who 
proposed 7 odor classes, two of which (fragrant and aromatic) were considered as pleasant. Men rarely wore fragrances at that time, and consequently Linnaeous probably regarded as fragrant those odors (floral and balsamic) suitable for women's fragrances. Conversely, he applied 'aromatic' to pleasant aromas not suitable for a woman's fragrance. Interestingly, the perfume category most typically masculine (fougère) is called 'aromatic' by Edwards (2010). Thus, the vertical axis of Fig. 2 could also be interpreted as a psychological dimension that distinguishes fragrant vs. aromatic scents.

Hedonic tones yield a statistically significant correlation with $\mathrm{p}[\mathrm{y}]$ because some notes used in men’s fragrances like ‘smoky’ or 'musty’ smell unpleasant, which is for sure well known by professional perfumers. Nonetheless, a major contribution of the present work is the fact that this relationship between hedonic aspects and masculine/feminine character was quantified statistically probably for the first time. This observed correlation can be explained by assuming that the most unpleasant odors used in perfumery yield certain similarity with 'earthy', which is a clearly masculine descriptor and the most dissimilar to 'floral'. Earthy notes are reminiscent of decomposition because they give the impression of freshly turned earth, forest soil, mold, must, yeast, and mushrooms. Rotten meat smells sulfurous, which would explain the position of the latter not far from 'earthy' in Fig. 2. Consistent with this hypothesis, 'sulfurous' and 'alliaceous' are placed next to 'earthy' in the flavor wheel proposed by Rowe (2000), which agrees with the masculine character of 'onion' (Kerr et al., 2005). In the SAFC matrix, 'sulfurous' yields the highest similarity with 'meaty' and 'alliaceous' ( $\mathrm{c}_{\mathrm{ov}}=36 \%$ and $29 \%$, respectively).

The two underlying dimensions that show up (top vs. base notes and masculine vs. feminine odors) are obviously related to functionality in perfumery. Thus, odor descriptors 
that map close to one another in the 2-D solutions seem to refer to materials that have some common sensory properties as well as common functionality. Fig. 2 and consistent sensory odor maps (Calkin \& Jellinek, 1994; Zarzo \& Stanton, 2009; Edwards, 2010) were developed by perfumers or by statistical analysis of odor descriptions from experts. Consequently, it could be argued that such representations reflect the functional classification that perfumers had in mind for fragrances. Of course, odors that are perceptually similar may tend to be functionally similar through learning and vice versa, which complicates the matter. Nonetheless, odor maps obtained from untrained subjects in market research also reflect the same two underlying descriptive dimensions (Jellinek, 1992; Richardson, 1999 p. 156), even when using consumers from different countries (see Fig. 1 of Zarzo, 2013). In order to investigate to what extent the sensory odor maps tell us anything in terms of perceptual similarity rather than functional similarity of the materials, one approach would be to obtain matrices of rated similarity by direct comparison between scented products and discuss the resulting MDS projection.

\subsection{Towards a standard sensory wheel of fragrance categories}

Different 2-D sensory maps of odor descriptors and olfactory families have been proposed in the perfumery field, for example the Rosace of Firmenich, Analogies of Givaudan, the Drom Fragrance Circle, the Discodor (Harder, 1979), the Hexagon of fragrance families (Haldiman \& Schuenemann, 1990), the Field of Odors (Jaubert et al., 1995), the natural perfume wheel (Aftelier, 2006), the wheel of natural extracts (Mane, 2014), the flavor wheel (Rowe, 2000), etc.. Although descriptors in these maps are basically the same, their relative position differs considerably and it is not straightforward to achieve a consensus scheme. Other representations have been derived from the multivariate analysis of comprehensive olfactory databases (Abe et al., 1990; Madany- 
Mamlouk et al., 2003), but they do not resemble any of these sensory maps. Both databases were re-analyzed here and the statistical methodology led to a two-dimensional solution (Fig. 2) quite different with respect to the mentioned odor maps. However, Fig. 2 is consistent with the Odor Effects Diagram (Jellinek, 1997), with odor maps derived from consumer research (Thiboud, 1991; Jellinek, 1992; Richardson, 1999) as well as those obtained from statistical analyses of odor profile databases (Zarzo \& Stanton, 2009). It is important to highlight that Fig. 2 resembles the well-known Fragrance Wheel (Edwards, 2010), which has been used by the Fragrance Foundation to create a directory that sorts more than 4,700 commercial fragrances (www.fragrancedirectory.info).

Results reported here suggest that it is possible to reach certain standard about how to plot olfactory families on a sensory wheel. Although there are already plenty of such representations in the perfume field, the consensus plot obtained (Fig. 2) is based on two meaningful dimensions (masculine vs. feminine and light vs. heavy scents) and it is supported by statistical analyses of comprehensive olfactory databases. Nevertheless, the fact that a 2D space accounts for a good portion of the variance of some databases does not imply that these two dimensions are sufficient to represent properly the perfume perceptual space. Previous work using sorting task of perfumes (e.g. Veramendi et al., 2013) showed that more than two dimensions were necessary to display the similarity between perfumes.

A recent study (Teixeira et al., 2014) uses a fragrance wheel that does not agree with Fig. 2 because 'woody' and 'citrus' appear next to each other. However, both descriptors are negatively correlated in Dravnieks' Atlas $(r=-0.20)$ and in the B-H database $(r=-0.06)$, which indicates that they are rarely applied together when describing aroma chemicals. Moreover, citrus scents are typically encountered in top notes of 
perfumes but rarely in base notes, while the opposite applies to woody odors (see Table 1 of Zarzo, 2013). Thus, further research about how to reach standard fragrance maps is still required.

\subsection{Final remark}

Despite the unavoidable dispersion in the position of descriptors when comparing different perfumery odor maps from the literature, it is striking that the two underlying dimensions that build up those maps are basically the same in most cases, as it was found in the three databases compared here. As a consequence, it is possible to achieve certain standard odor map for the main descriptors used in perfumery, which would be useful to facilitate the communication between professionals. This standard will require a broad discussion and consensus among the perfumery community, but it will be of great value for fragrance description and classification because it provides valuable information to understand the similarities and dissimilarities among perfumery descriptors and olfactory families.

\section{ACKNOWLEDGEMENTS}

I am grateful to R. Vitale for the preparation of the olfactory datasets. 


\section{REFERENCES}

Abe, H., Kanaya, S., Komukai, T., Takahashi, Y., \& Sasaki, S. (1990). Systemization of semantic descriptions of odors. Analytica Chimica Acta, 239, 73-85.

Aftelier (2006). Natural perfume wheel. Berkeley, CA: Aftelier Perfumes Inc.

Arctander S. (1969). Perfume and flavor chemicals (aroma chemicals) (Vol. I and II). Montclair, NJ: S. Arctander publisher.

Boelens, H., \& Haring, H. G. (1981). Molecular structure and olfactive quality. Bussum, The Netherlands: Internal Report, Naarden International.

Borg, I., \& Groenen, P. J. F. (2005). Modern Multidimensional Scaling: Theory and Applications (2nd ed.). New York: Springer.

Brud, W. S. (1986). Words versus odors: How perfumers communicate. Perfumer \& Flavorist, 11(4), 27-44.

Buja, A., \& Swayne, D. F. (2002). Visualization methodology for multidimensional scaling. Journal of Classification, 19, 7-43.

Calkin, R. R., \& Jellinek, J. S. (1994). Perfumery: Practice and principles. (1st ed.). New York: Wiley.

Castro, J. B.; Ramanathan, A.; Chennubhotla, C. S. (2013). Categorical dimensions of human odor descriptor space revealed by non-negative matrix factorization. PLoS ONE, 8(9), e73289.

Chastrette, M., Elmouaffek, A., \& Sauvegrain, P. (1988). A multidimensional statistical study of similarities between 74 notes used in perfumery. Chemical Senses, 13, 295305.

Chastrette, M., de Saint Laumer, J. Y., \& Sauvegrain, P. (1991). Analysis of a system of description of odors by means of four different multivariate statistical methods. Chemical Senses, 16(1), 81-93.

Dravnieks, A., Masurat, T., \& Lamm, R. A. (1984). Hedonics of odors and odor descriptors. Journal of the Air Pollution Control Association, 34(7), 752-755.

Dravnieks, A. (1985) Atlas of odor character profiles, data series DS 61. Philadelphia, PA: American Society for Testing and Materials.

Edwards, M. (2010). Fragrances of the world: Parfums du monde 2010. (26th ed.). Sydney: Fragrances of the World.

Glöss, W. (Ed.) (1991). H\&R fragrance guide: Feminine and masculine notes. (2nd ed.). Hamburg, Germany: Glöss Verlag. 
Gower, J. C. (1966). Some distance properties of latent root and vector methods used in multivariate analysis. Biometrika, 53, 325-338.

Haldiman, R. F., \& Schuenemann, T. (1990). The hexagon of fragrance families. Dragoco Report, 37, 83-89.

Harder, U. (1979). Der H\&R duftkreis. Haarmann \& Reimer Contact, 23, 18-27. An updated version in English available at:

http://www.leffingwell.com/h\%26rfragrance/Fragrance\%20Families.pdf (accessed 2 October 2014).

Jasper, A., \& Wagner, N. (2008). Notes on scent. Cabinet, 32. Available at: http://cabinetmagazine.org/issues/32/jasper_wagner.php (accessed 2 October 2014).

Jaubert, J. N., Tapiero, C., \& Doré, J. C. (1995). The field of odors: Toward a universal language for odor relationships. Perfumer \& Flavorist, 20(3), 1-16.

Jellinek, J. S. (1992). Perfume classification: A new approach. In S. Van Toller, \& G. H. Dodd (Eds.), Fragrance: The psychology and biology of perfume (pp. 229-242). London: Chapman \& Hall.

Jellinek, J. S. (1997). The psychological basis of perfumery: A re-evaluation. In J. S. Jellinek (Ed.), The psychological basis of perfumery (4th ed., pp. 240-256). London: Chapman \& Hall.

Jolliffe, I. T. (2002). Principal component analysis. (2nd ed.). New York: Springer.

Kerr, K. L., Rosero, S. J., \& Doty, R. L. (2005). Odors and the perception of hygiene. Perceptual \& Motor Skills, 100(1), 135-141.

Khan, R. M., Luk, C. -H., Flinker, A., Aggarwal, A., Lapid, H., Haddad, R., \& Sobel, N. (2007). Predicting odor pleasantness from odorant structure: Pleasantness as a reflection of the physical world. Journal of Neuroscience, 27(37), 10015-10023.

Koulakov, A., Kolterman, B. E., Enikolopov, A. G., \& Rinberg, D. (2011). In search of the structure of human olfactory space. Frontiers in Systems Neuroscience, 5, 65.

Kraft, P., Bajgrowicz, J. A., Denis, C., \& Fráter, G. (2000). Odds and trends: Recent developments in the chemistry of odorants. Angewandte Chemie International Edition, 39, 2980 - 3010.

Li, W., Luxenberg, E., Parrish, T., \& Gottfried, J. A. (2006). Learning to smell the roses: Experience-dependent neural plasticity in human piriform and orbitofrontal cortices. Neuron, 52(6), 1097-1108. 
Lingle, T. R. (1992). The coffee cuppers' handbook: A systematic guide to the sensory evaluation of coffee's flavor. Long Beach, CA: Specialty Coffee Association of America.

Linnaeus, C. (1756). Odores medicamentorum. In Amoenitates Academicae (Vol. 3, pp. 183-201). Stockholm, Sweden: Lars Salvius.

Madany-Mamlouk, A., Chee-Ruiter, C., Hofmann, U. G., \& Bower, J. M. (2003). Quantifying olfactory perception: Mapping olfactory perception space by using multidimensional scaling and self-organizing maps. Neurocomputing, 52-54, 591-597.

Mane (2014). Flavor and fragrance ingredients catalogue 2014-2015. Available at: http://mane.com/sites/default/files/catalogue_mane_ingredients_2014-15.pdf (acceseed 15 January 2015).

Meilgaard, M. C., Dalgliesh, C. E., \& Clapperton, J. F. (1979). Beer flavour terminology. Journal of the Institute of Brewing, 85, 38-42.

Mojet, J., \& De Jong, S. (1994). The sensory wheel of virgin olive oil. Grasas y Aceites, 45, 42-47.

Müller, J. (1992). The H\&R book of perfume: Understanding fragrance; origins, history, development; guide to fragrance ingredients. Hamburg, Germany: Glöss Verlag.

Noble, A., Arnold, R. A., Buechsentein, J., Leach, E., Schmidt, J. O., \& Stern, P. M. (1987). Modification of a standardized system of wine aroma terminology. American Journal of Enology and Viticulture, 38, 143-146.

Pintore, M., Wechman, C., Sicard, G., Chastrette, M., Amaury, N., \& Chretien, J. R. (2006). Comparing the information content of two large olfactory databases. Journal of Chemical Information and Modeling, 46, 32-38.

Richardson, A. (1999). Measurement of fragrance perception. In D. H. Pybus, \& C. S. Sell (Eds.), The chemistry of fragrances (chapter 8, pp. 145-157). Cambridge, UK: The Royal Society of Chemistry.

Rowe, D. (2000). More fizz for your buck: High-impact aroma chemicals. Perfumer \& Flavorist, 25(5), 1-19.

Sigma-Aldrich. 2003. Flavors and fragrances 2003-2004 catalog. Milwaukee, WI: SigmaAldrich Fine Chemicals Company. 
Teixeira, M. A., Barrault, L., Rodríguez, O., Carvalho, C. C., \& Rodrigues, A. E. (2014). Perfumery radar 2.0: A step toward fragrance design and classification. Industrial \& Engineering Chemistry Research, 53(21), 8890-8912.

Thiboud, M. (1991). Empirical classification of odors. In P. M. Müller, \& D. Lamparsky (Eds.), Perfumes: Art, science and technology (pp. 253-286). New York, NY: Elsevier.

Tisserand, R. (1988). Essential oils as psychotherapeutic agents. In S. Van Toller, \& G. H. Dodd (Eds.), Perfumery: The psychology and biology of fragrance (pp. 167-181). London: Chapman \& Hall.

Veramendi, M., Herencia, P., \& Gastón, A. (2013). Perfume odor categorization: to what extent trained assessors and consumers agree? Journal of Sensory Studies, 28(1), 7689.

Wilson, D. A, \& Stevenson, R. J. (2003). The fundamental role of memory in olfactory perception. Trends in Neuroscience, 26(5), 243-247.

Zarzo, M., \& Stanton, D. T. (2006). Identification of latent variables in a semantic odor profile database using principal component analysis. Chemical Senses, 31(8), 713724.

Zarzo, M.; Stanton, D. T. (2009) Understanding the underlying dimensions in perfumers' odor perception space as a basis for developing meaningful odor maps. Attention, Perception \& Psychophysics, 71, 225-247.

Zarzo, M. (2008). Relevant psychological dimensions in the perceptual space of perfumery odors. Food Quality \& Preference, 19, 315-322.

Zarzo, M. (2011). Hedonic judgments of chemical compounds are correlated with molecular size. Sensors, 11, 3667-3686.

Zarzo, M. (2013) What is a fresh scent in perfumery? Perceptual freshness is correlated with substantivity. Sensors, 13, 463-483. 


\section{FIGURE CAPTIONS}

Fig. 1. Loading plots obtained by applying PCA to the double-centered matrix of Abe et al. (1990) ( $\mathbf{T}_{\text {Abe). Left: }}$ [2] vs. p[1]; right: p[4] vs. p[3]. Related descriptors are joined with solid lines.

Fig. 2. Loading plot for PC1/PC2 (p[2] vs. p[1]) obtained from the database of Boelens \& Haring (1981) (filled diamonds) superimposed with the consensus loading plot (white squares) obtained from the matrix $\mathbf{W}_{\text {Abe }}$ (Abe et al., 1990) and $\mathbf{W}_{\text {SAFC }}$ (Sigma-Aldrich, 2003); horizontal axis: $\left(\mathrm{p}[1]_{\mathrm{Abe}}+\mathrm{p}[2]_{\mathrm{SAFC}}\right) / 2$; vertical axis: $\left(\mathrm{p}[2]_{\mathrm{Abe}}+\mathrm{p}[1]_{\mathrm{SAFC}}\right) / 2$.

Fig. 3. Comparison between three representations of olfactory descriptive space in the context of perfumery: i) diagram of Calkin \& Jellinek (1994) (inner square, letters in italics); ii) fragrance wheel of Edwards (2010) (intermediate sensory wheel that displays odor classes within circles); iii) Discodor (Harder, 1979) (outer odor wheel). A reorganization of the Discodor is proposed (outer terms in italics).

Fig. 4. Modified Drom Fragrance Circle. Numbers indicate the sequence of categories in the original representation. 
Table 1.

PCA results from three olfactory databases: comparison of $\mathrm{p}[1]$ and $\mathrm{p}$ [2] values (loadings in the formation of PC1 and PC2) obtained from $\mathbf{W}_{\text {Abe }}$ (weighted matrix of Abe et al., 1990), $\mathbf{W}_{\text {SAFC }}$ (weighted SAFC matrix) and database of Boelens \& Haring (1981). The hedonic tone of descriptors is also included as well as useful parameters obtained from the H\&R Fragrance Guide (Glöss, 1991).

\begin{tabular}{|c|c|c|c|c|c|c|c|c|c|c|c|c|c|}
\hline \multirow[b]{2}{*}{ DESCRIPTOR } & \multicolumn{2}{|c|}{ Hedonic tone $\mathrm{a}^{\mathrm{a}}$} & \multicolumn{3}{|c|}{ H\&R guide } & \multicolumn{3}{|c|}{ Abe et al. (1990) } & \multicolumn{3}{|c|}{ SAFC matrix } & \multicolumn{2}{|c|}{ Boelens \& Haring } \\
\hline & $\mathrm{HT}_{\mathrm{D} 84}$ & $\mathrm{HT}_{\mathrm{D} 85}$ & $\mathrm{SI}^{\mathrm{b}}$ & $\% \mathrm{~F}^{\mathrm{c}}$ & $\% \mathrm{M}^{\mathrm{c}}$ & $N^{d}$ & $\mathrm{p}[1]$ & $\mathrm{p}[2]$ & $N^{d}$ & $\mathrm{p}[1]$ & $\mathrm{p}[2]$ & $\mathrm{p}[1]$ & $\mathrm{p}[2]$ \\
\hline Alliaceous & -0.17 & -9 & & & & 0.4 & & & 3.3 & -0.147 & 0.142 & & \\
\hline Anisic & 1.21 & 3 & 9 & 2.2 & 13.9 & 1.8 & & & 1.4 & & & -0.081 & 0.045 \\
\hline Animal & -1.13 & -16 & 100 & 39.3 & 5.7 & 3.8 & -0.127 & 0.138 & 1.5 & -0.084 & -0.119 & -0.142 & -0.056 \\
\hline Balsamic & & & 100 & 13.9 & 3.5 & 9.0 & -0.173 & 0.365 & 3.0 & 0.180 & -0.082 & -0.249 & -0.043 \\
\hline Buttery & 2.04 & -2 & & & & 1.7 & & & 2.8 & -0.039 & -0.117 & -0.023 & 0.129 \\
\hline Camphoraceous & -0.55 & 4 & & & & 3.7 & -0.145 & -0.095 & 2.4 & -0.074 & -0.104 & & \\
\hline Caramel & 2.32 & 0 & & & & 2.5 & & & 2.0 & 0.129 & -0.208 & & \\
\hline Cheese & 1.02 & & & & & 0.3 & & & 2.4 & -0.051 & -0.073 & & \\
\hline Chocolate & 2.78 & 1 & & & & & & & 2.3 & -0.124 & -0.226 & & \\
\hline Citrusy & 2.72 & 8 & 0 & 3.5 & 11.2 & 2.4 & 0.161 & 0.081 & 6.5 & 0.135 & 0.233 & 0.189 & 0.010 \\
\hline Coffee & 2.33 & -1 & & & & 0.4 & & & 2.7 & -0.244 & -0.040 & & \\
\hline Creamy & & & & & & 1.0 & & & 1.9 & 0.000 & -0.040 & & \\
\hline Earthy & -1.94 & -11 & 100 & 15.9 & 49.0 & 4.4 & -0.215 & -0.142 & 3.6 & -0.070 & 0.223 & -0.008 & -0.395 \\
\hline Ethereal & -1.54 & 0 & & & & 9.5 & 0.054 & -0.045 & 5.4 & 0.110 & 0.000 & & \\
\hline Fatty & -1.41 & -13 & & & & 6.5 & 0.210 & -0.071 & 5.0 & 0.065 & 0.262 & 0.166 & 0.101 \\
\hline Floral & 2.79 & 14 & 48 & 98.5 & 67.3 & 27.0 & -0.119 & 0.385 & 20.1 & 0.377 & 0.004 & -0.010 & 0.223 \\
\hline Fruity & 2.23 & 11 & 8 & 33.1 & 1.9 & 32.2 & 0.249 & 0.025 & 36.4 & 0.312 & -0.019 & 0.085 & 0.248 \\
\hline Gassy & -2.3 & -10 & & & & 2.7 & -0.011 & -0.122 & & & & & \\
\hline Green & 2.19 & -2 & 7 & 34.2 & 24.0 & 22.1 & 0.096 & -0.231 & 14.1 & 0.032 & 0.343 & 0.279 & -0.116 \\
\hline Herbaceous & 0.97 & 0 & 3 & 2.2 & 44.7 & 20.6 & -0.200 & -0.153 & 8.5 & 0.081 & 0.008 & & \\
\hline Honey & 2.08 & 4 & 69 & 11.7 & 10.4 & 3.1 & 0.041 & 0.227 & 2.6 & 0.266 & 0.016 & -0.064 & 0.104 \\
\hline Lavender & 2.25 & 10 & 6 & 1.5 & 60.8 & 0.4 & & & & & & 0.128 & -0.076 \\
\hline Leafy & 1.34 & -1 & 0 & 7.5 & 0.5 & 3.2 & 0.045 & -0.036 & & & & & \\
\hline Meaty & -1.64 & -13 & & & & & & & 5.4 & -0.221 & 0.040 & & \\
\hline Medicinal & -0.89 & 2 & & & & 2.7 & -0.301 & -0.075 & 3.0 & -0.111 & -0.179 & -0.052 & -0.180 \\
\hline Metallic & -0.94 & -6 & & & & 1.8 & & & & & & 0.165 & -0.161 \\
\hline Minty & 2.5 & 6 & 3 & 0.0 & 2.2 & 2.3 & -0.123 & -0.091 & 3.5 & -0.004 & -0.125 & 0.045 & -0.120 \\
\hline Musky & 0.21 & 3 & 100 & 83.4 & 87.2 & 2.5 & -0.144 & 0.031 & & & & & \\
\hline Musty & -1.94 & -11 & 100 & 15.9 & 49.0 & 5.1 & -0.220 & -0.249 & 2.6 & -0.094 & 0.177 & & \\
\hline Nutty & 1.92 & -3 & & & & 2.5 & -0.127 & -0.111 & 7.0 & -0.247 & -0.148 & & \\
\hline Oily & -1.41 & -13 & & & & 12.0 & 0.181 & -0.103 & 4.3 & -0.050 & 0.070 & & \\
\hline Orange & 2.86 & 7 & 1 & 6.6 & 9.8 & 1.9 & 0.257 & 0.117 & 1.5 & & & & \\
\hline Powdery & -0.07 & 3 & 100 & 53.2 & 36.8 & 0.6 & & & & & & -0.323 & -0.045 \\
\hline Rosy & 3.08 & 8 & 50 & 87.9 & 49.9 & 9.0 & 0.121 & 0.276 & 6.0 & & & & \\
\hline Smoky & -1.53 & -10 & & & & 0.7 & & & 1.6 & -0.281 & 0.034 & -0.144 & -0.265 \\
\hline Spicy & 1.99 & 7 & 30 & 24.5 & 80.9 & 7.4 & -0.329 & 0.028 & 5.2 & 0.052 & -0.295 & -0.182 & -0.176 \\
\hline Sulfurous & -2.45 & -15 & & & & 0.8 & & & 1.6 & -0.140 & 0.138 & & \\
\hline Sweet & 2.03 & 18 & 88 & 34.0 & 14.4 & & & & 16.0 & 0.238 & -0.275 & -0.280 & 0.206 \\
\hline Vanilla & 2.57 & 3 & 100 & 41.9 & 30.2 & 1.9 & -0.265 & 0.301 & 1.9 & 0.077 & -0.311 & -0.221 & 0.122 \\
\hline Vegetable & 1.58 & -7 & 21 & 4.0 & 34.6 & 2.3 & 0.041 & -0.321 & 2.2 & -0.060 & 0.315 & 0.126 & -0.316 \\
\hline Waxy & 0.96 & 6 & 0 & 29.4 & 1.9 & 2.9 & 0.165 & 0.058 & 3.2 & 0.174 & 0.199 & & \\
\hline Woody & 0.94 & 3 & 82 & 39.7 & 80.1 & 9.5 & -0.315 & -0.157 & 13.3 & -0.321 & -0.114 & -0.124 & -0.258 \\
\hline
\end{tabular}


${ }^{\mathrm{a}} \mathrm{HT}_{\mathrm{D} 84}$ : hedonic tones from Dravnieks et al. (1984); $\mathrm{HT}_{\mathrm{D} 85}$ : hedonic tones calculated by applying PCA to the Atlas of Dravnieks (1985).

${ }^{\mathrm{b}}$ Substantivity index (see Equation 1 of Zarzo, 2013). The values 0 and 100 correspond to descriptors that only appear in the description of top and base notes, respectively.

${ }^{\mathrm{c}}$ Percentage of feminine $(\% \mathrm{~F})$ and masculine $(\% \mathrm{M})$ fragrances in the H\&R Guide (Glöss, 1991) whose top, middle or base notes are labeled with each descriptor.

${ }^{\mathrm{d}}$ Percentage of ingredients in the database labeled with each descriptor. 